\title{
Application of Continuous Wavelet Transform based on Fast Fourier Transform for the Quality Analysis of Arc Welding Process
}

Vikas Kumar ( $\square$ iamvikasjha@gmail.com )

Kalinga Institute of Industrial Technology https://orcid.org/0000-0003-1503-8944

\section{Subhadip Ghosh}

Kalinga Institute of Industrial Technology

Manoj Kumar Parida

Kalinga Institute of Industrial Technology

Shaju K Albert

Indira Gandhi Centre for Atomic Research

\section{Research Article}

Keywords: Continuous wavelet transforms, Signal processing, Arc welding, Welding skill, Metal transfer, Shielding gas

Posted Date: July 20th, 2021

DOI: https://doi.org/10.21203/rs.3.rs-666437/v1

License: (c) (i) This work is licensed under a Creative Commons Attribution 4.0 International License. Read Full License 


\title{
Application of Continuous Wavelet Transform based on Fast Fourier Transform for the Quality Analysis of Arc Welding Process
}

\author{
Vikas Kumar $^{1 *}$, Subhadip Ghosh ${ }^{1}$, Manoj Kumar Parida1 ${ }^{1}$ and Shaju K Albert ${ }^{2}$ \\ ${ }^{1}$ School of Electronics Engineering, Kalinga Institute of Industrial Technology, Bhubaneswar \\ ${ }^{2}$ Metallurgy \& Materials Group, Indira Gandhi Centre for Atomic Research, Kalpakkam \\ 1*E-Mail: - iamvikasjha@gmail.com / vikas.jhafet@kiit.ac.in
}

\begin{abstract}
SMAW (Shielded Metal Arc Welding) and GMAW (Gas Metal Arc Welding) are two of the most prominent welding processes commonly utilized in almost all types of modern industries. Among various aspects of these processes, some of the important parameters that govern the quality of the final weld product are the skill level of welders, welding consumables, and the role of shielding gases (in GMAW). Currently, the role of these parameters in determining the quality of the welded product is examined by evaluating the final weld produced and not by investigating how these factors actually affect the welding process. This is an indirect way to evaluate such welding parameters, which are both time-consuming and expensive. During the actual welding process, random variations in arc signals (voltage and current) take place. These dynamic variations are so short and rapid that ordinary ammeters and voltmeters cannot monitor the rate of such variations. However, the reliable acquisition of such variations and its subsequent analysis can provide very useful information in determining the quality of the final weld product. In this study, arc voltage and current were acquired at 100,000 samples/sec, filtered and subsequently analyzed using Continuous Wavelet Transform based on Fast Fourier Transform (CWT-FFT) technique to evaluate welding skill, welding electrodes (in SMAW process), and the effect of shielding gases (in GMAW process). Results thus obtained clearly differentiated the skill level of different trainee welders and welding electrodes in the SMAW process and the effect of shielding gases and arc current in the GMAW process. Very good correlation among the obtained results, its weld bead and weld pool images were observed. Hence, this research proposes a simple yet effective methodology to evaluate the arc welding process parameters using CWT-FFT analysis of the welding signals.
\end{abstract}




\section{Keywords}

Continuous wavelet transforms, Signal processing, Arc welding, Welding skill, Metal transfer, Shielding gas

\section{Introduction}

Arc welding is one of the most commonly and widely used welding process in almost all types of modern industries for joining various ferrous and non-ferrous metals. Due to its inherent merits like the ease of use, versatility, flexibility, and low maintenance cost this process finds its application in fabricating almost everything we see around us like buildings, bridges, locomotives \& coaches, general machinery, defence equipment etc. This process has many variants (like SMAW, GMAW, GTAW etc.) and the primary differences between these processes are the methods by which the molten metal is protected from the atmosphere [1]. Due to its unpredictable arc behaviour and complicated modes of metal transfer, arc welding has stochastic characteristics and therefore, dynamic fluctuations in arc voltage and current were observed during actual welding. The quality of the final weld product depends heavily on various welding parameters that create these random fluctuations. Consequently, if these variations that occur during the actual welding process are suitably acquired and processed then, the effect of various arc welding parameters like the skill of welders, the role of shielding gases and consumables etc on the final weld product can be understood in a much better way than it is done at present. However, such dynamic variations in arc voltage and current occur for very short intervals of time. Therefore, to record such variations, a high-speed data acquisition and monitoring system (along with relevant sensors), capable of acquiring arc variations at the same rate as they occur should only be used. In order to establish an effective weld monitoring system, many researchers have used techniques like visible light imaging [2-3], voltage sensing [4-6], current sensing [5-6], acoustic emission [7-8] and vision sensing [9-15]. The processing units in such monitoring systems widely vary from Field Programmable Gate Arrays (FPGA) [16], Microprocessors [17], Microprocessors [18], System on Chips (SoCs) [19] and Analog to digital cards [20]. Recently, a general-purpose and commonly available DSO has also been used to establish an effective weld monitoring system [21-23].

Weld data obtained from such monitoring systems have been used to evaluate welding parameters using various statistical [24-25, 19, 21-23] and Artificial Neural Network (ANN) techniques [26-28]. Furthermore, 
several signal processing techniques like Short Time Fourier Transforms (STFT), Fourier Transform (FT), etc were also extensively employed to enhance the reliability of the welding signal [21-23]. But, FT and STFTs have the limitations of localization of frequency components [41]. Therefore, other advanced signal processing algorithms like Continuous Wavelet Transform (CWT) and Discrete Wavelet Transforms (DWT) are widely adopted in the literature to process the non-stationarity of welding signals [29-38]. Wavelet transforms are essentially a Multi-Resolution analysis (MRA) technique that can be used to obtain the time-frequency representation of the Welding signal. MRA is designed to give good time resolution and poor frequency resolution at high frequencies and good frequency resolution and poor time resolution at low frequencies [21]. Chen et. al in [29] has developed a wavelet-based algorithm to extract Al alloy weld pool in GTAW process and subsequently proposed the idea of intelligentized welding manufacturing technology. Das et. al in [30] have used the wavelet transform technique to identify tunnel type of defects in an FSW process and for this, the authors have analyzed the real-time force signal by amalgamating the properties of wavelet and Hilbert-Huang transform. Lv et al [31] have proposed a wavelet transform based denoising algorithm for the GTAW process [32]. Similarly, in [33-38] the authors have used the denoising property of the wavelet transform to denoise the noisy welding signal by maintaining a soft threshold and subsequently extracting various process parameters to evaluate the welding process.

In the present study, welding signal (arc voltage and current) and weld pool image were acquired using a highspeed Digital Storage Oscilloscope (DSO) and a high-speed camera set up. Subsequently, evaluation of the welder's performance, welding electrodes in the SMAW process and the role of shielding gases in a GMAW process were done by analyzing the resultant welding signals. The analysis presented in this work was carried out using both statistical and CWT based signal processing techniques. Detailed analysis on the results thus obtained and their practical implications are suitably delineated in this paper. But, before proceeding to experimental setup details, a brief description of the methodologies of Continuous Wavelet Transform based on Fast Fourier Transform (CWT-FFT) technique used in this study is given below. 


\section{CWT-FFT based Methodology}

CWT essentially represents the correlation between continuous input signal " $x(t)$ " and a suitable wavelet function shown below.

$$
\begin{aligned}
& C w(a, b)=\int_{-\infty}^{+\infty} x(t) \psi_{a, b}^{*} d t \\
= & \frac{1}{\sqrt{a}} \int_{-\infty}^{+\infty} x(t) \psi^{*}\left(\frac{t-b}{a}\right) d t
\end{aligned}
$$

Here, $\psi_{(\mathrm{t})}^{*}$ represents the complex conjugate of original mother wavelet $\psi(t)$ [39-40], $C w(a, b)$ is a function of the wavelet's dilation " $a$ " and translation " $b$ " parameters [39-40]. The energy normalized factor $\frac{1}{\sqrt{a}}$ is an integral coefficient [41]. However, a wavelet must have finite energy as per the following mathematical criteria

$$
\begin{aligned}
& E=\int_{-\infty}^{+\infty}|\psi(t)|^{2} d t<\infty \quad \text { and } \quad C_{\psi}=\int_{-\infty}^{+\infty} \frac{\left|\psi^{\wedge}(\omega)\right|^{2}}{\omega} d \omega<\infty \\
& \hat{\psi}(\omega)=\int_{-\infty}^{+\infty} \psi(t) e^{-i \omega t} d t
\end{aligned}
$$

Where $\omega$ represents angular frequency and $\psi(\omega)$ is the Fourier transform of mother wavelet $\psi(t)$. The condition presented with equation (2) and (3) is also known as the condition of admissibility and generally based on how fast $\left|\psi^{\wedge}(\omega)\right|^{2}$ tends to zero compared to $\frac{1}{\omega}$. This condition implies that $\hat{\psi}(\omega)=0$ and that the wavelet has no frequency component. $C_{\psi}$ refers to admissibility constant whose value essentially depends on the type of chosen wavelet [42]. The CWT thus obtained results in a two-dimensional scalogram function $E(a, b)=$ $\left|C_{\mathrm{w}}(a, b)\right|^{2}$ depicting the energy distribution as a function of scales " $a$ " and positions " $b$ ". Using equation 4 scale " $a$ " can be transformed to frequency of wavelet " $f_{a}$ ". This clearly indicates that at $a=1$ and $b=0$, the wavelet's associated frequency becomes the mother wavelet's characteristic frequency. Therefore the $f_{c}$ used in a CWT essentially indicates the whole frequency content in the wavelet and unlike Fourier analysis in CWT the signal is not decomposed of numerous sinusoidal frequencies [39].

$$
f_{a}=\frac{f_{c}}{a}
$$


Since, equation 5 describes the inverse wavelet transform, it should be able to reconstruct the original signal if the wavelet coefficients are known. Here, $K_{\psi}$ is constant whose value is determined by the type of wavelet similarly, $D(a, t)$ is the details function whose value is given by equation (6).

$$
\begin{gathered}
\begin{array}{c}
x(t)=\frac{1}{K_{\psi}} \int_{a=0}^{+\infty}\left(\int_{b=-\infty}^{+\infty} C w(a, b) \psi_{a, b}(t) \frac{d b}{a^{2}}\right) d a \\
=\frac{1}{K_{\psi}} \int_{0}^{+\infty} D(a, t) d a
\end{array} \\
D(a, t)=\int_{b=-\infty}^{+\infty} \frac{1}{a^{2}} C w(a, b) \psi_{a, b}(t) d b
\end{gathered}
$$

For most of the practical applications, wavelet series or wavelet coefficients are used to reconstruct the original and this in turn heavily depends on the selection of appropriate wavelet function. The classical CWT presented till now is time consuming and requires high computing resources for its operation. Hence, in recent years modified and efficient way to compute CWT using FFT algorithms have evolved [39-42] by simply re-defining the CWT of equation 1 to equation (8).

$C w(a, b)=\int_{-\infty}^{+\infty} x(t) \psi_{a b}^{*}(t) d t=\int_{-\infty}^{+\infty} x(t) \psi_{a}^{*}(b-t) d t$

where, $\psi_{a}(t)=\frac{1}{\sqrt{a}} \psi\left(\frac{t}{a}\right)$ and $\psi_{a b}(t)=\frac{1}{\sqrt{a}} \psi\left(\frac{t-b}{a}\right)$

It is evident from equations 8 and 9 that CWT is now just a simple convolution of the signal with the wavelet. As a result, a CWT can be considered an inverse Fourier transform.

$C w(a, b)=\frac{1}{2 \pi} \int_{-\infty}^{+\infty} \hat{x}(\omega) \hat{\psi_{a, b}^{*}}(\omega) d \omega$

where, $\hat{\psi}_{a, b}^{*}(\omega)=\sqrt{a} \hat{\psi}^{*}(a \omega) e^{i \omega b}$ indicates the Fourier transform of the processed wavelet and $\hat{x}(\omega)=$ $\int_{-\infty}^{+\infty} x(t) e^{-i \omega t} d t$ is the Fourier transform of the signal $x(t)$

Similarly, to the preceding explanation, if the signal is discrete in nature, a Discrete Wavelet Transform may be implemented to analyze the relevant signal to extract various signal parameters. If $x(n)$ is a discrete signal having " $N$ " number of samples, the convolution equation used earlier can be expressed as equation (11). From 
this equation the DWT can be easily calculated by simply convolving the signal and wavelets for each position value and iterating the same for each scale $a$ as well.

$W_{a}(b)=\sum_{n=0}^{N-1} x(n) \psi_{a}^{*}(b-n)$

Consequently, for two periodic signals specified by equation (11), the circular convolution can be calculated using equation (12) [43].

$\sum_{n=0}^{N-1} x(n) \psi_{a}^{*}(b-n)=\frac{1}{N} \sum_{k=0}^{N-1} \hat{x}(k) \hat{\psi}_{a}^{*}(k) e^{i \frac{2}{N} k b}, b=0,1,2 \ldots N-1$

where, DFT of $\mathrm{x}(\mathrm{n})$ is given by $\hat{x}(k), \hat{\psi}_{a}$ is the DFT of $\psi_{a}$ and $k$ is the frequency index.

$\hat{x}(k)=\sum_{n=0}^{N-1} x(n) e^{-i \frac{2 \pi}{N} n k}, k=0,1,2 \ldots N-1$

$\hat{\psi}_{a}(k)=\sum_{n=0}^{N-1} \psi_{a}(n) e^{-i \frac{2 \pi}{N} n k}, k=0,1,2 \ldots N-1$

If $f_{s}$ is the signal sampling frequency with sampling period $\Delta t$, then the wavelet function can also be normalized to obtain the unit energy at each and every scale " $a$ " using equation (15).

$\hat{\psi}_{a}\left(a \omega_{k}\right)=\sqrt{\frac{2 \pi a}{\Delta t}} \hat{\psi}\left(a \omega_{k}\right)$

where, $\omega_{k}=\frac{2 \pi k}{N \Delta t}$ and the CWT then can also be defined using equation 16 [39].

$W_{a}(b)=\frac{1}{N} \sqrt{\frac{2 \pi a}{\Delta t}} \sum_{k=0}^{N-1} \hat{x}\left(\frac{2 \pi}{N \Delta t} k\right) \hat{\psi^{*}}\left(a \frac{2 \pi}{N \Delta t} k\right) e^{2_{\mathrm{H}} k}$

The methodologies described above were used to analyze the arc welding signal to evaluate various arc welding parameters. As described in [41], in the present work also, the calculations were performed using different wavelets i.e., Derivative of Gaussian, Morlet and Paul etc. Additionally, all the available wavelet types were examined using the MATLAB version (2016a). From the rigorous analysis of the wavelets and their properties the non-analytic Morlet wavelet with zero mean was chosen as a candidate wavelet for our present study as its 
scalogram provided similar information consistent with the known process parameters of an arc welding process (i.e., short circuit metal transfer duration etc.) [21-23].

\section{Experimental Setup}

Fig. 1 shows the complete schematic of the experimental setup used in this study. The setup used basically comprises of a data acquisition, welding and a high-speed camera setup. Brief descriptions about these modules are given below.

\subsection{Data acquisition setup}

For all our studies data acquisition was carried out to acquire the instantaneous values of voltage and current by maintaining an identical condition while making bead-on-plate welding on a carbon steel plate using suitable welding consumables. In order to acquire the arc voltage and current, a general-purpose Digital Storage Oscilloscope (DSO7054B) of Agilent Technologies (now Keysight) having a maximum sampling rate of 4 GSa/seconds and bandwidth of $500 \mathrm{MHz}$ was used. DSO7054B has 4 channels with inbuilt AC to DC coupling. The input impedance of DSO was $50-1 \mathrm{M} \Omega$ and an in-depth memory of 8 M-Points. For sensing welding current, Hall Effect based highly sensitive current clamp (600 A DC and 100 A AC) was used. Similarly, in order to sense arc voltage, a differential probe having $500 \mathrm{MHz}$ bandwidth was used. To achieve high Common Mode Rejection Ratio (CMRR) and to match the overall frequency and attenuation response two signal paths along the measurement were provided. The system has an input capacitance of $2.5 \mathrm{pF}$ and a propagation delay of $6.1 \mathrm{~ns}$. Welding duration was set to 20 seconds and arc voltage and current were acquired at 100,000 samples /seconds. The acquired data were then filtered for noise and in turn used for subsequent analysis.

\subsection{Welding setup}

To evaluate the welding skill in the SMAW process, iinstantaneous current and voltage values were recorded by making bead-on-plate welds on carbon steel using an inverter power source and E 7018 electrodes of 3.15 mm diameter. Similarly, in order to compare different welding electrodes by comparing their arc characteristics welding data were acquired from bead on plate welds on carbon plates using basic coated (E 7018, $3.15 \mathrm{~mm}$ diameter) and cellulose coated electrodes (E 6010 of $2.5 \mathrm{~mm}$ diameter) and an inverter power source. 
To investigate the effect of shielding gases in the GMAW process bead-on-plate welding on carbon plate using AWS ER 70S2 wires (of $1.2 \mathrm{~mm}$ diameter) were made by varying the shielding gas and current combinations as shown in Table 1. From this table, it can be seen that for each shielding gas, three different current combinations were used to obtain different modes of metal transfer. It should be noted that all welds are prepared using the same welder and machine.

\subsection{High speed camera setup}

To visualize the metal transfer behavior of welding electrodes and correlate the same with the acquired electrical signal a Fastcam MC2.1 photon focus high speed camera with suitable filters and illumination were used. This camera setup had a maximum capture speed of 10,000 frames/sec with the minimum shutter opening time of $1 / 100,000 \mathrm{~s}$. Please note that in this study, metal transfer images of various welding electrodes were captured at 5000 frames/sec. Photograph of the DSO based high speed data acquisition, welding and high-speed camera imaging setup is shown in Fig. 2.

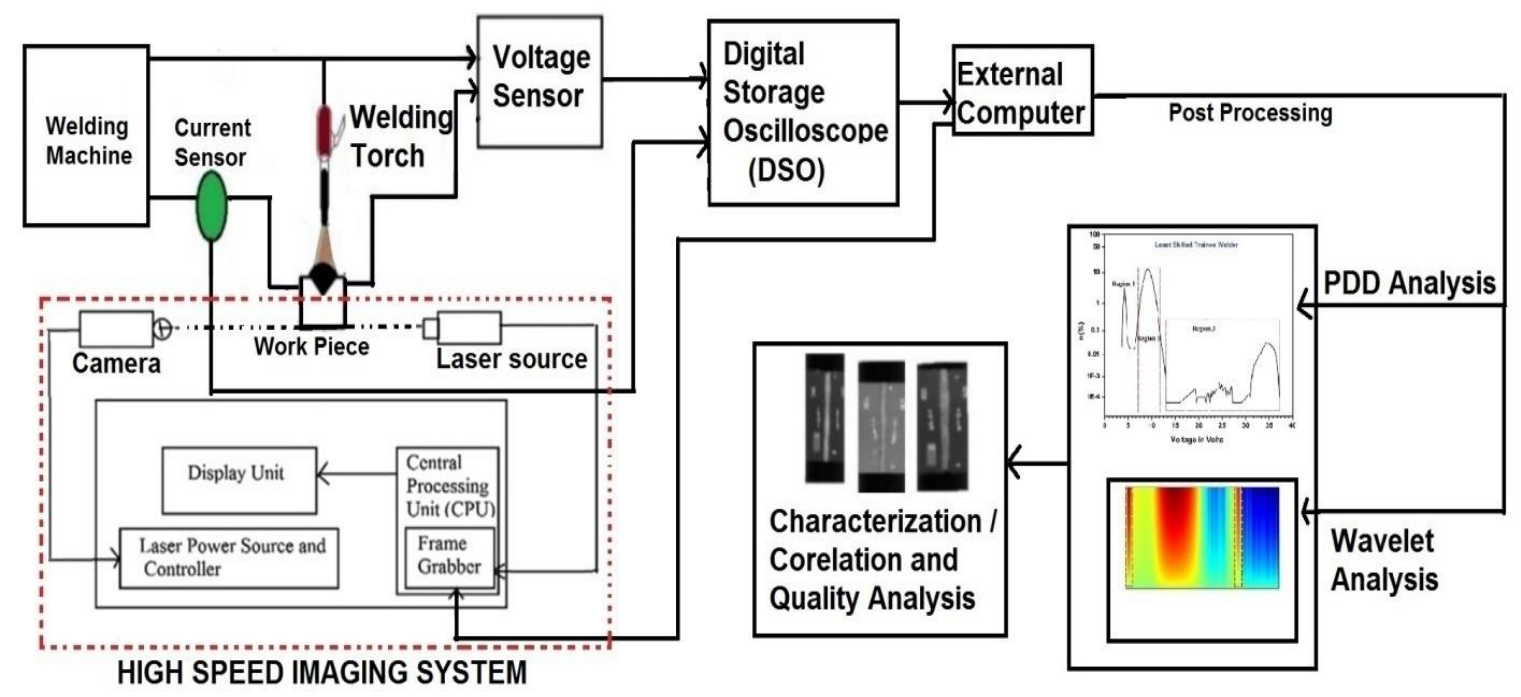

Fig. 1: Schematic of the complete experimental setup

Table 1: Composition of shielding gases used in GMAW process

\begin{tabular}{|l|l|}
\hline \multicolumn{1}{|c|}{ Gas Composition } & \multicolumn{1}{c|}{ Set Current } \\
\hline $80 \% \mathrm{Ar}$ and $20 \% \mathrm{Co} 2$ & (a) 200 A (b) 220 A (c) 300 A \\
\hline $100 \% \mathrm{Ar}$ & (a) 190 A (b) 220 A (c) 240 A \\
\hline $100 \% \mathrm{Co} 2$ & (a) 150 A (b) 200A \\
\hline
\end{tabular}



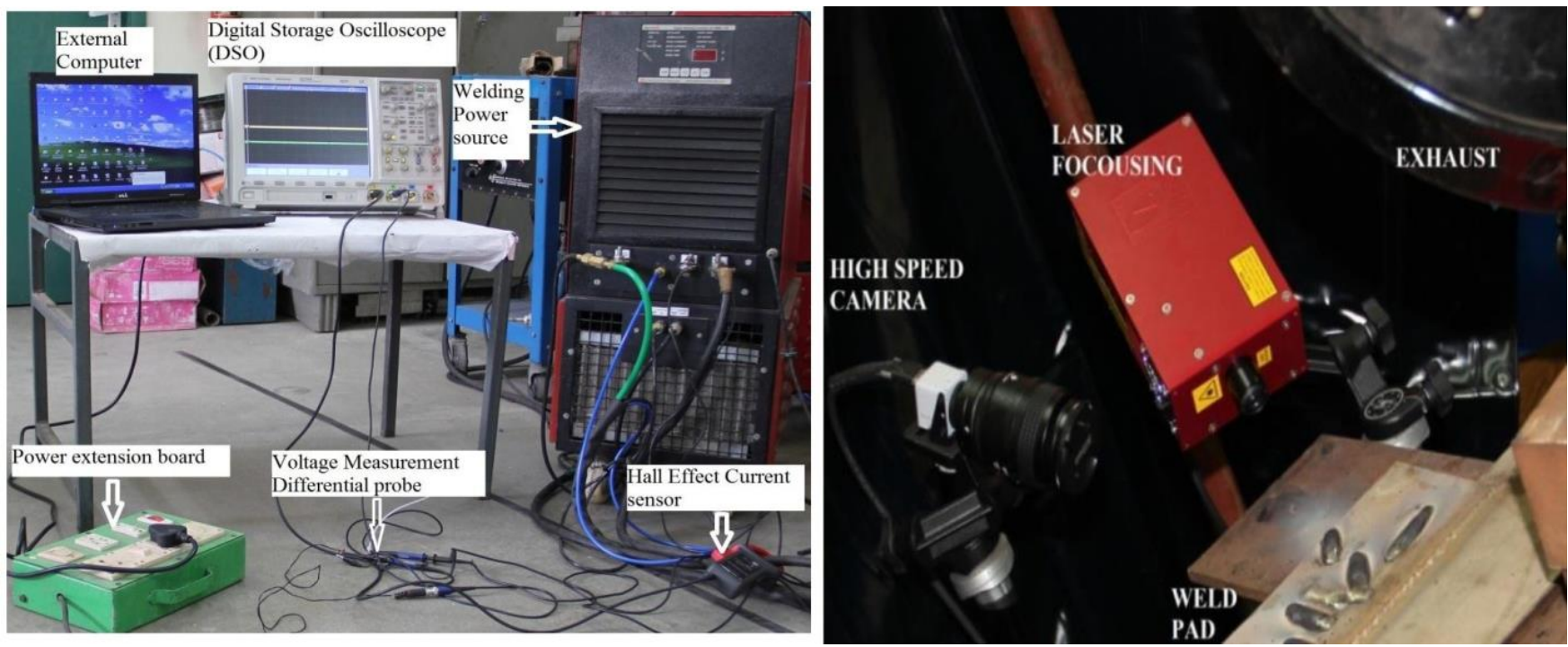

Fig. 2: Photograph of (a) the weld data acquisition setup and (b) high speed camera setup

\section{Results and Discussion}

\subsection{Evaluation of Welding Skill}

Fig. 3 depicts the time domain analysis of an unskilled and a skilled trainee welder, in this figure steady-state voltage values and sharp dips from this steady-state can be easily noticed (only $500 \mathrm{~ms}$ data are shown for clarity purpose). The sudden decrease in voltage values actually corresponds to the short circuit mode of metal transfer in the molten weld pool from an E 7018 (basic type) welding electrode [23]. A careful comparison of Fig 3 (a) and Fig 3 (b) reveals that the voltage fluctuations in the oscillogram of an unskilled welder are more than that of a skilled welder. The un-skilled welder has not learnt the welding skill yet and therefore finding it difficult to maintain a constant arc gap. Contrary, a skilled welder knows how to perform steady-state welding and therefore lesser variations with frequent short circuit metal transfers (SC1, SC2 etc.) can be easily noticed.

Probability Density Distribution (PDD) $[\mathbf{1 9 , 2 1 - 2 3 ]}$ plot of the voltage signal acquired using an unskilled and skilled welder and E7018 electrode used to plot Fig. 3 is shown in Fig. 4. From this figure it is clear that, in general, the voltage PDD will have three distinct regions (region 1 to region 3), region 1 will be around low voltages, whereas region 2 will be around the mid voltage values. The mid voltage values around region 2 actually correspond to the mean voltages displayed by the voltmeter of the welding power source whereas region 1 indicates the short circuit metal transfer happening in welding pool with E 7018 electrodes. Similarly, region 3 
of the voltage PDD (towards the higher voltages) corresponds to the hand stability of the trainee welder to maintain a uniform arc gap. Fig 4 (b) shows the voltage PDD made by a skilled welder, from this figure it is clear that for a good weld made with E 7018 type of basic electrode, voltage PDD should have two distinct and widely separated regions 1, 2 and should have least variations in region 3 (Fig. 4 (b)). On the other hand, the voltage PDD obtained from an unskilled welder in Fig. 4 (a) reveals that an untrained welding personal will have significantly lesser values of region 1 and 2 with large random variations in region 3 (Fig. 4 (a)). Therefore, it is clear that a good welder must have wider region 2 (steady state welding duration) and narrower region 3 (duration of unstable welding). To validate the hypothesis presented just now the bead image and its corresponding radiographs (for skilled and unskilled welders) are shown in Fig. 5. Comparing, Fig. 4 and 5, it is now indeed clear that for a good weld, the welding duration of region 2 must be as wide as possible because wider region 2 ensures more voltage values at steady-state and consequently lesser arc gap variations. Similarly, to ensure stable arc gap variations the duration of region 3 must be as small as possible. Based on the explanations presented above, the durations of region 2 and 3 were evaluated using the CWT based FFT methodology described in section 3.
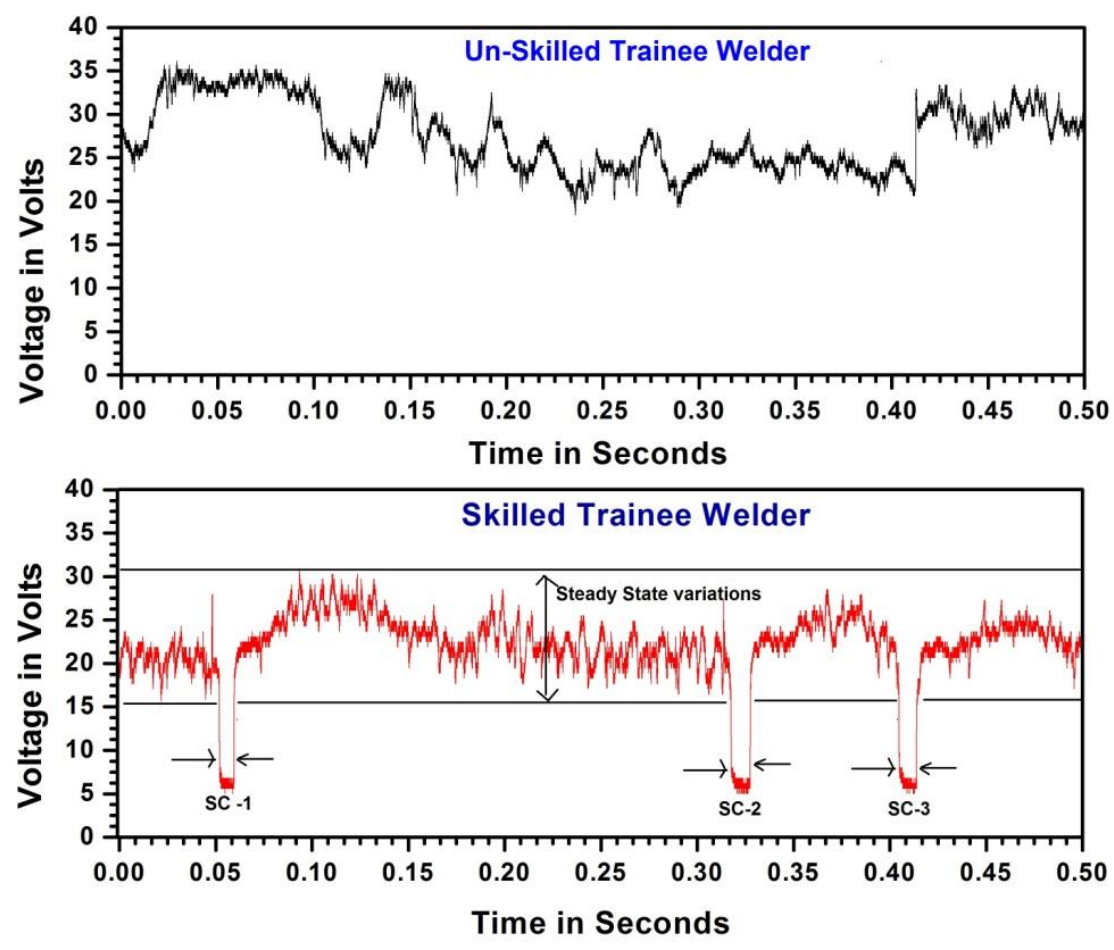

Fig. 3: Time domain oscillogram of (a) Unskilled and (b) skilled welder 

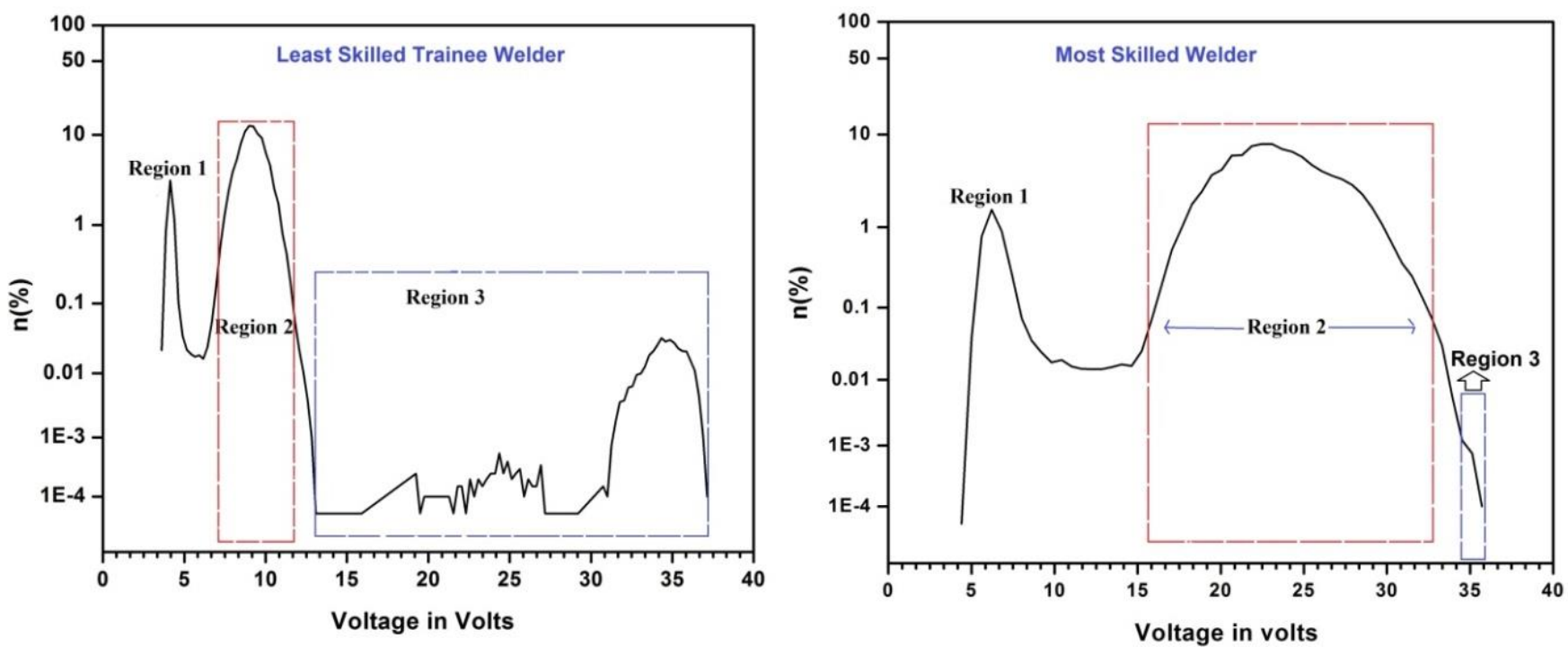

Fig. 4: PDD analysis of (a) Unskilled and (b) skilled welder
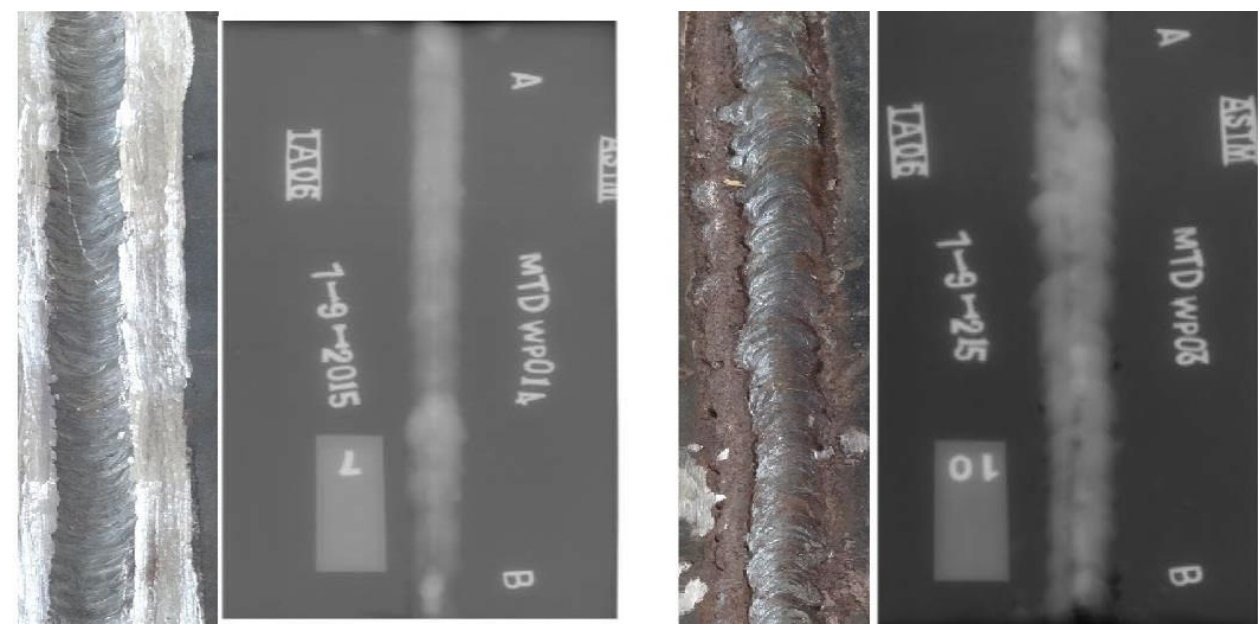

Fig. 5: Bead image and radiographs of (1) skilled and (2) Unskilled welder

Fig 6 represents the scalogram (described in section 3) of the voltage PDD of the skilled and unskilled welder (same welders used to plot Fig 3 and 4), from this figure one can easily note that the welding duration of region 2 ( 11 seconds) for the skilled welder is far greater than the Region 2 duration ( 4 seconds) for unskilled welder. Similarly, region 3 duration for skilled welder was around 1 seconds and the duration of the same for the unskilled welder was nearly 14 seconds. The analysis just now presented clearly differentiated the skill level of skilled and un-skilled welder and gives us the flexibility to grade the skill levels of trainee welders by monitoring the durations of two regions of the voltage PDD using CWT-FFT technique for any welder. 

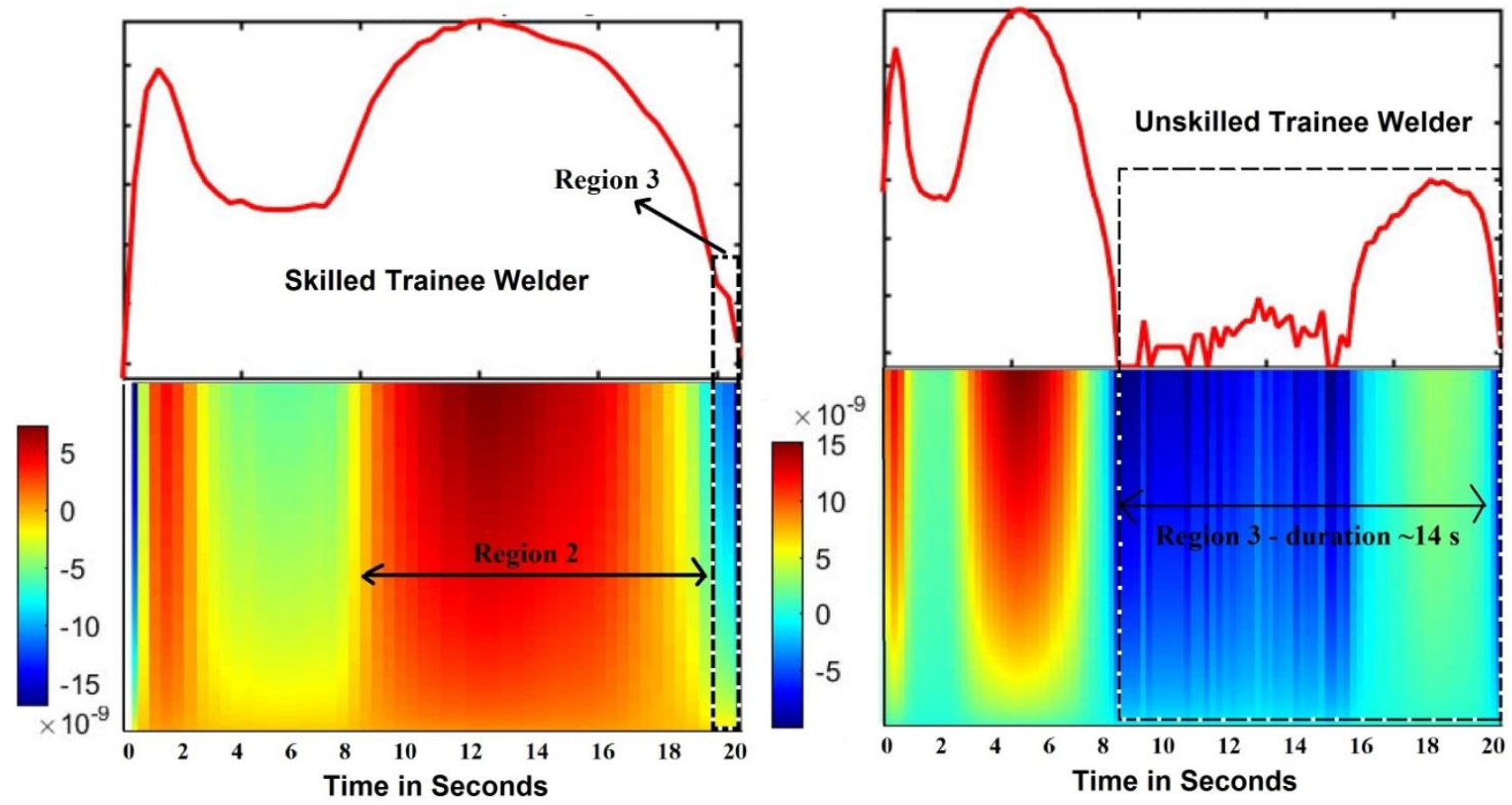

Fig. 6: CWT-FFT analysis of the voltage PDD of (1) skilled and (2) Unskilled welder
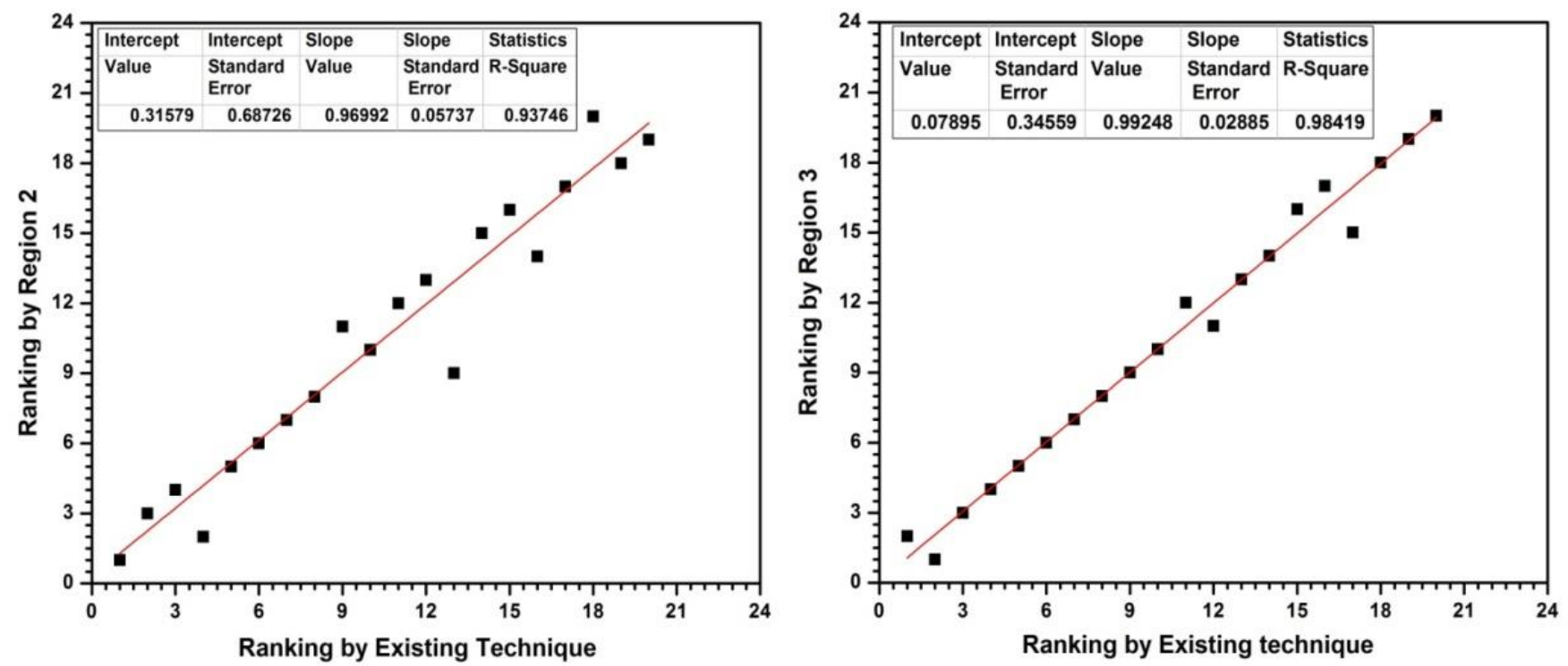

Fig. 7: Correlation between the ranks proposed by current and proposed methodology.

In order to really confirm the results obtained above in grading the skill levels of trainee welders, similar analysis needs to be performed on larger sets of trainee welders. Therefore, 20 passing out trainee welder from a weld training institute were examined by monitoring the welding durations of region 2 and 3 as proposed above 
and their corresponding rankings are tabulated in Table 2. The ranking obtained in turn were correlated with the current practice of ranking the welding skill using PDD analysis [21-22] and by performing the visual examinations of their final weld bead. From this table and referring to Fig. 7, a very good correlation between the proposed and current practice of weld skill classification were noticed.

Table 2: Comparison of the welding skill using proposed method with its current practice

\begin{tabular}{|c|c|c|c|c|}
\hline $\begin{array}{c}\text { Welder } \\
\text { ID }\end{array}$ & $\begin{array}{c}\text { PDD Rank } \\
\text { Region } 3 \text { [23] }\end{array}$ & $\begin{array}{c}\text { Ranking by monitoring the } \\
\text { welding duration of Region } 2 \\
\text { (Using proposed method) }\end{array}$ & $\begin{array}{c}\text { PDD Rank } \\
\text { Region } 3 \text { [23] }\end{array}$ & $\begin{array}{c}\text { Ranking by monitoring the } \\
\text { welding duration of Region } 3 \\
\text { (Using proposed method) }\end{array}$ \\
\hline 15 & 1 & 1 & 2 & 1 \\
\hline 8 & 2 & 3 & 3 & 3 \\
\hline 14 & 4 & 2 & 7 & 7 \\
\hline 6 & 5 & 5 & 12 & 11 \\
\hline 7 & 6 & 6 & 14 & 14 \\
\hline 3 & 20 & 19 & 20 & 20 \\
\hline 13 & 19 & 18 & 10 & 10 \\
\hline 9 & 7 & 7 & 11 & 12 \\
\hline 10 & 8 & 8 & 9 & 9 \\
\hline 12 & 9 & 11 & 17 & 15 \\
\hline 17 & 18 & 20 & 19 & 19 \\
\hline 19 & 11 & 12 & 8 & 8 \\
\hline 1 & 12 & 13 & 4 & 4 \\
\hline 11 & 13 & 9 & 15 & 16 \\
\hline 16 & 3 & 4 & 5 & 5 \\
\hline 5 & 14 & 15 & 13 & 13 \\
\hline 20 & 15 & 16 & 6 & 6 \\
\hline 18 & 16 & 14 & 1 & 2 \\
\hline 2 & 17 & 17 & 18 & 18 \\
\hline 4 & 10 & 10 & 16 & 17 \\
\hline
\end{tabular}

\subsection{Evaluation Welding Consumable}

For evaluating the welding electrodes high speed data acquisition and camera setup described in section 3 was used to acquire welding voltage and current and to capture the metal transfer behavior in E 7018 and E 6010 types of welding consumables. High speed camera image in Fig $\mathbf{8}$ clearly depicts the metal transfer behavior in 
such electrodes, it is observed that in E 7018 types of basic electrodes short circuit types of metal transfer is predominant whereas in cellulosic electrodes (E 6010 types), both short circuit and spray modes of metal transfer were noticed. This observation was in agreement with those reported in [22]. To study the arc behavior of the individual electrodes their metal transfer characteristics were correlated with their voltage PDDs (Fig 8). In this correlation the region of short circuit and spray transfer in E 7018 and E 6010 electrodes respectively can be easily seen.
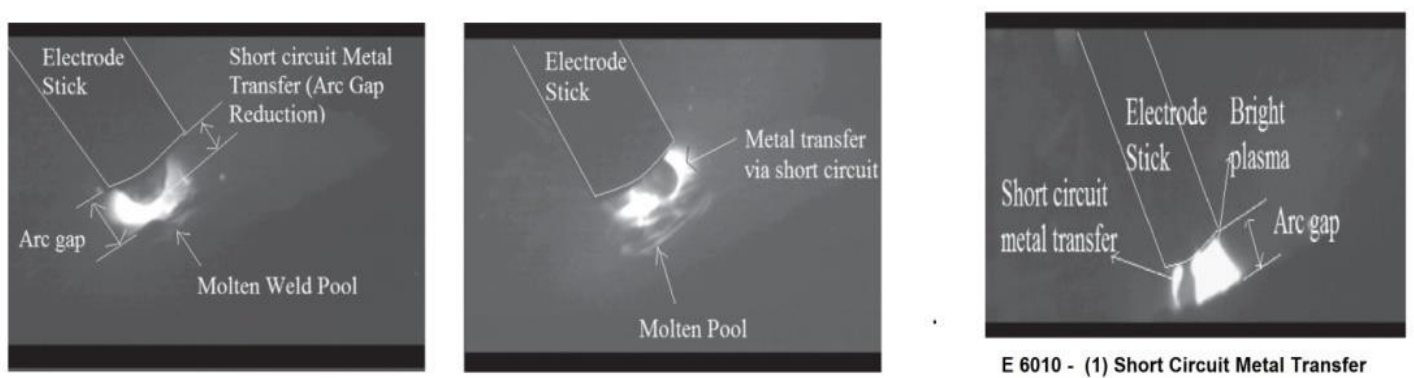

E 6010 - (1) Short Circuit Metal Transfer
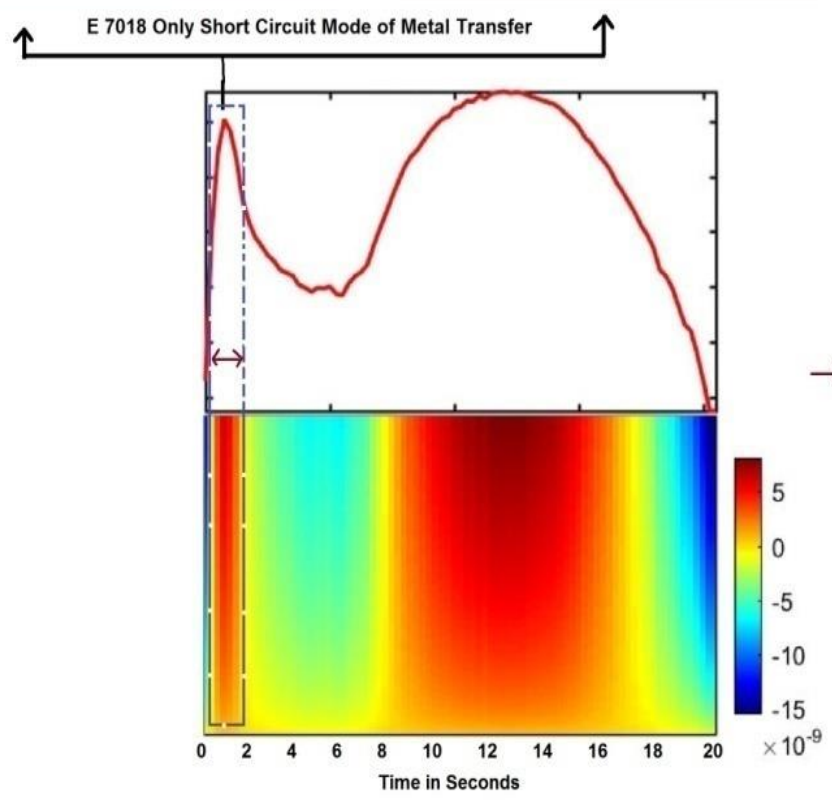

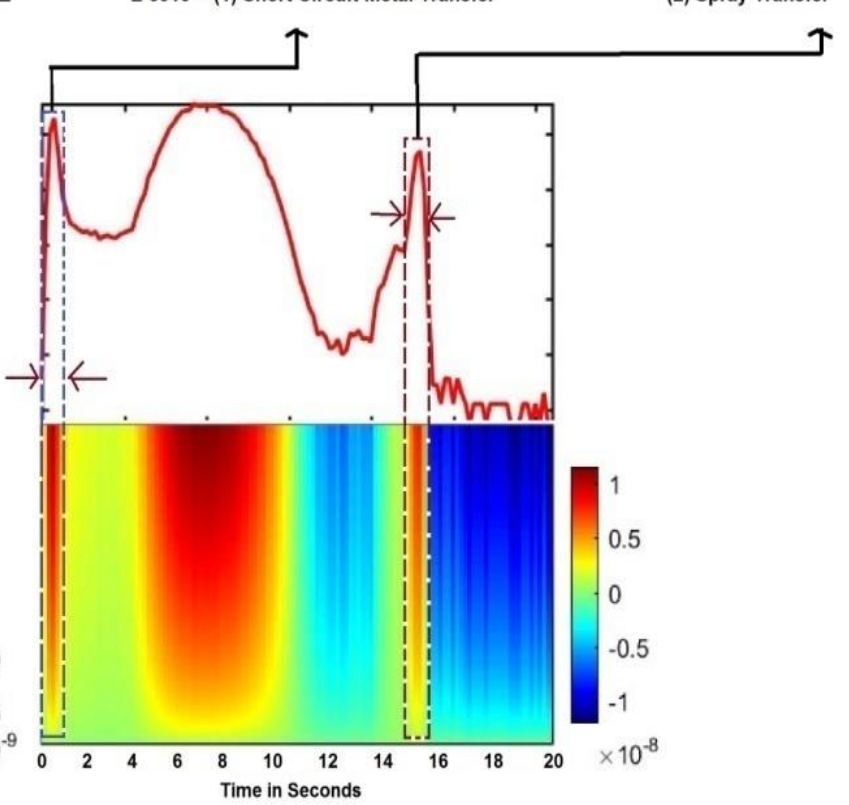

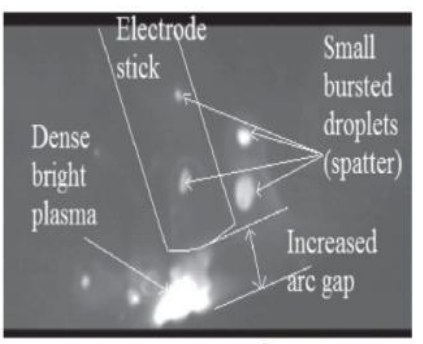

(2) Spray Transfer

Fig. 8: CWT-FFT analysis of the voltage PDD and its correlation with pool image of (1) basic $\mathbf{E} 7018$ and (2) cellulosic E 6010 electrodes

CWT-FFT algorithm was also used on the voltage PDDs of E 7018 and E 6010 electrodes to quantify their metal transfer durations happening in the actual process. From the CWT-FFT scalogram of the voltage PDD in Fig. 8 obtained from these electrodes one can easily assess the duration of metal transfer of the individual 
electrodes. A careful analysis of this figure reveals that for E 7018 the duration of short circuit mode of metal transfer is nearly 2 seconds whereas in E 6010 electrodes the same is found to be approximately 1 second. Similarly, in addition to short circuit the duration of spray mode of metal transfer happening only in E 6010 electrodes were also observed to be around 1 second. These results were also correlated with the time domain analysis (oscillogram) of the arc voltage signals acquired during actual welding process and a very good correlation were observed between them.

\subsection{Effect of Shielding Gases in GMAW Process}

In a GMAW Process, depending on the composition of shielding gases and current combinations, the metal transfer mechanism can be either short circuiting, globular, or spray type [44]. Therefore, to know their exact behavior, we have used different gas compositions (Table 1) to find out whether changing modes of metal transfer can be correlated with its corresponding voltage and current signal. Fig. 9 represents the scalogram (using CWT-FT method) of the voltage PDD obtained for GMAW-P when $80 \% \mathrm{Ar}$ and $20 \% \mathrm{CO}_{2}$ gas composition was used. We can see from this figure that at around $200 \mathrm{~A}$, the duration of the first peak (or short circuit transfer) is around 3 seconds. Due to considerable duration of short circuit metal transfer spatter of molten droplets around the welded area may occur before separating from the wire on account of a mild explosion which takes place due to an increased current [45]. Therefore, many spatters can be noticed in its bead image shown in Fig 10 (a). With increasing current (from 200 A to 220 A) significant decrease in short circuit metal transfer duration was noticed ( 2 seconds) and consequently the spatter around the weld also decreased. A further increase in current (at around $300 \mathrm{~A}$ ), first peak of voltage PDD or the short circuit metal transfer duration totally disappeared (Fig. 9 (c)). Because for $80 \% \mathrm{Ar}$ and $20 \% \mathrm{CO}_{2}$ gas composition, at around $300 \mathrm{~A}$, spray mode of metal transfer start dominating [45]. Note that spatter around the welded area has significantly decreased now (Fig. 10 (c)). Results and the trends just now mentioned were in correlation with the time domain analysis of the shielding gas composition of $80 \% \mathrm{Ar}$ and $20 \% \mathrm{CO}_{2}$ (see Fig. 12 (a).) 


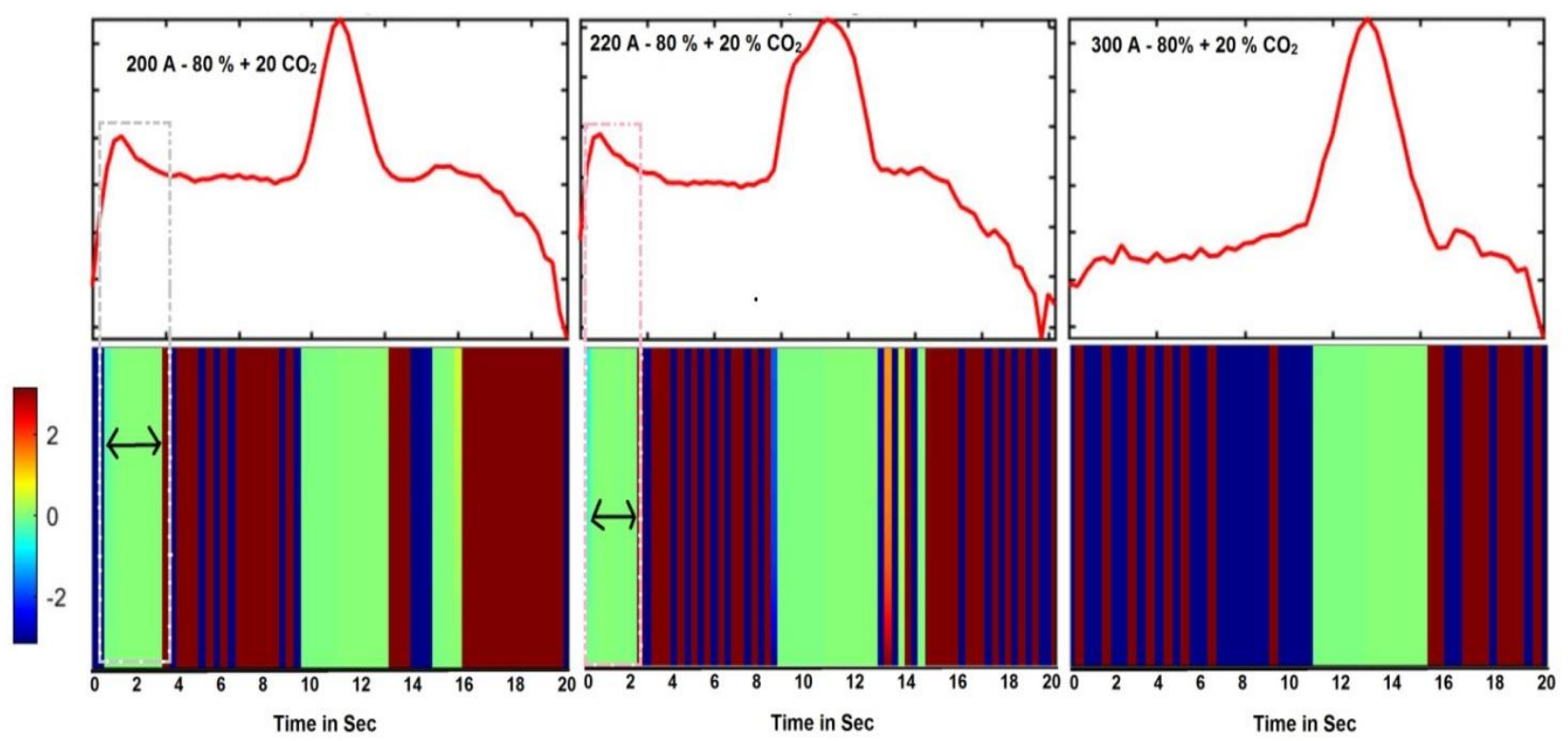

Fig. 9: CWT-FFT analysis of the voltage PDD of $80 \% \mathrm{Ar}$ and $20 \% \mathrm{CO}_{2}$ shielding gas composition in GMAW process at (a) $200 \mathrm{~A}$ (b) $220 \mathrm{~A}$ and (c) $300 \mathrm{~A}$

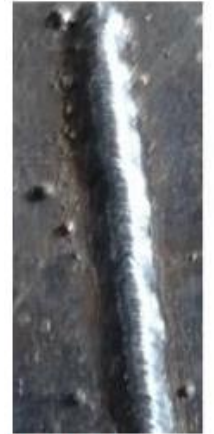

(a) $200 \mathrm{~A}$

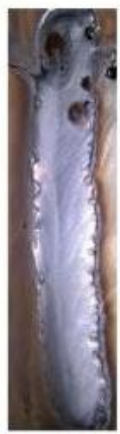

(b) $220 \mathrm{~A}$

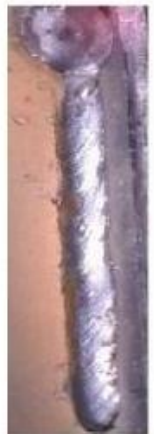

(c) $300 \mathrm{~A}$

Fig. 10: Bead images of the weld from $80 \% \mathrm{Ar}$ and $20 \% \mathrm{CO}_{2}$ shielding gas composition in GMAW process at (a) $200 \mathrm{~A}(\mathrm{~b}) 220 \mathrm{~A}$ and (c) $300 \mathrm{~A}$

Fig. 11 show the scalogram obtained using CWT-FFT analysis of the voltage PDD plotted by maintaining the shielding gas composition to $100 \% \mathrm{Ar}$ and by varying the current at three distinct levels $(190 \mathrm{~A}, 220 \mathrm{~A}$ and 240 A). A comparison of these figures with the one obtained by varying the shielding gas to $80 \%$ Ar and $20 \%$ $\mathrm{CO}_{2}$ gas mixtures (Fig. 9), indicates that the duration of first peak (or short circuit metal transfer) decreases as the current increases from $190 \mathrm{~A}$ to $240 \mathrm{~A}$ ( 4 seconds at $190 \mathrm{~A}, \sim 2$ seconds at $220 \mathrm{~A}$ and negligible duration at 240 A). This means that as the current increases from 190 A to 240 A, short circuit transfer gradually changes to globular transfer and then finally to spray transfer at around 240 A [45]. Readers should keep in mind that due to 
$100 \%$ Ar content; poor surface tension property may occur which may lead to very unstable and erratic welding characteristic. It may also be noted that although $100 \%$ Ar are not commonly used as a shielding gas in GMAWP, this study has included the same to show how variations in arc characteristics caused by variations in shielding gas composition can be investigated by noticing the short circuit duration using CWT-FFT analysis technique. Results just now presented are once again is in agreement with the time domain analysis of the $100 \% \mathrm{Ar}$ shielding gas composition shown in Fig. 12 (b).
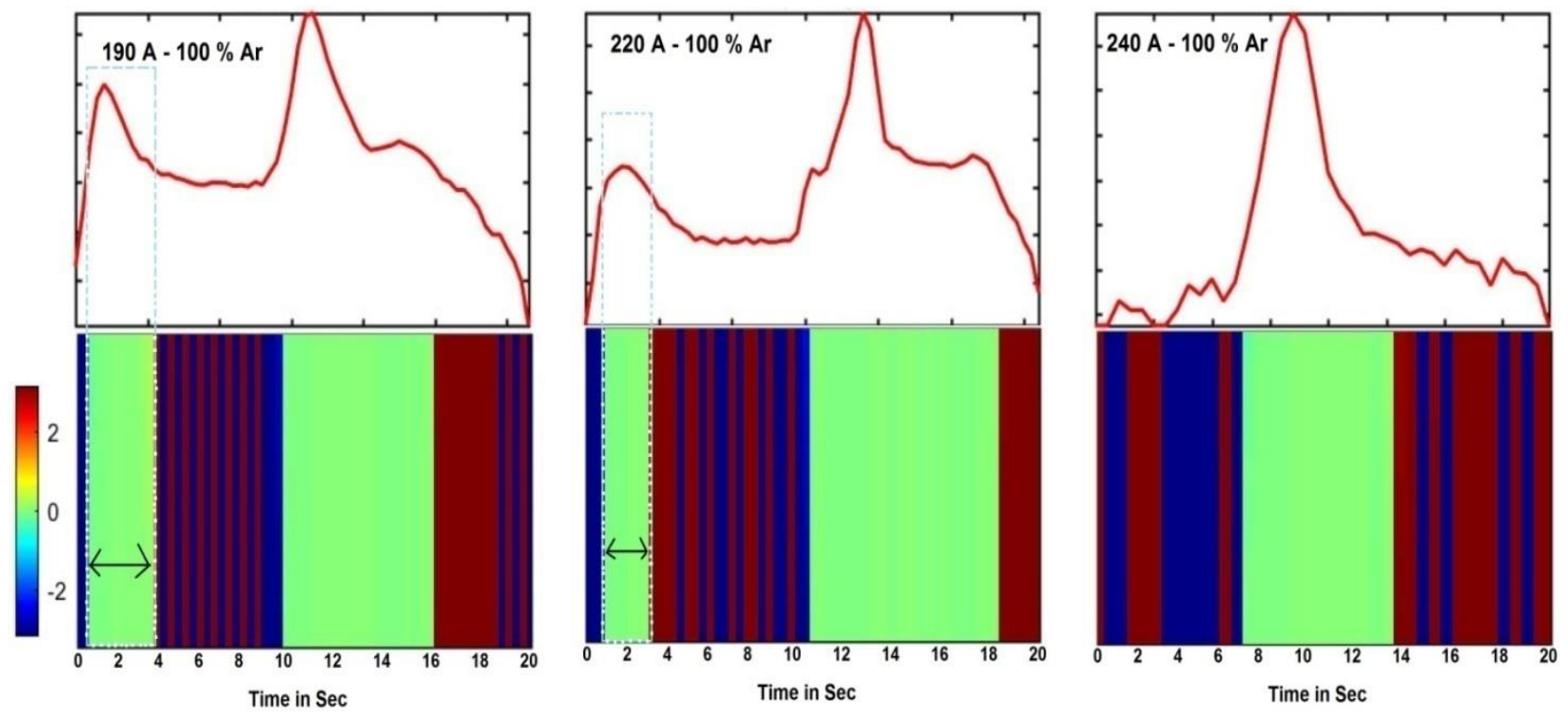

Fig. 11: Scalogram of voltage PDD of $100 \%$ Ar shielding gas in GMAW process at (a) $190 \mathrm{~A}$ (b) $220 \mathrm{~A}$ and (c) $240 \mathrm{~A}$

Fig. 13 and 14 shows the CWT-FFT of the voltage PDD and time domain analysis respectively of $100 \%$ $\mathrm{CO}_{2}$ shielding gas composition at different current levels. A careful examination of these figures clearly indicates that irrespective of current magnitude the short circuit duration of voltage PDD in CWT-FFT analysis and voltage dips (in time domain analysis) almost remains the same. This means that only short circuit or globular modes of metal transfers are dominant modes in $100 \% \mathrm{CO}_{2}$ shielding gas, there is no spray transfer associated with $100 \% \mathrm{CO}_{2}$ shielding gas. The results were in agreement with conclusion drawn in [46] where the authors found that for more than $20 \% \mathrm{CO}_{2}$, spray mode of metal transfer is difficult to achieve. 


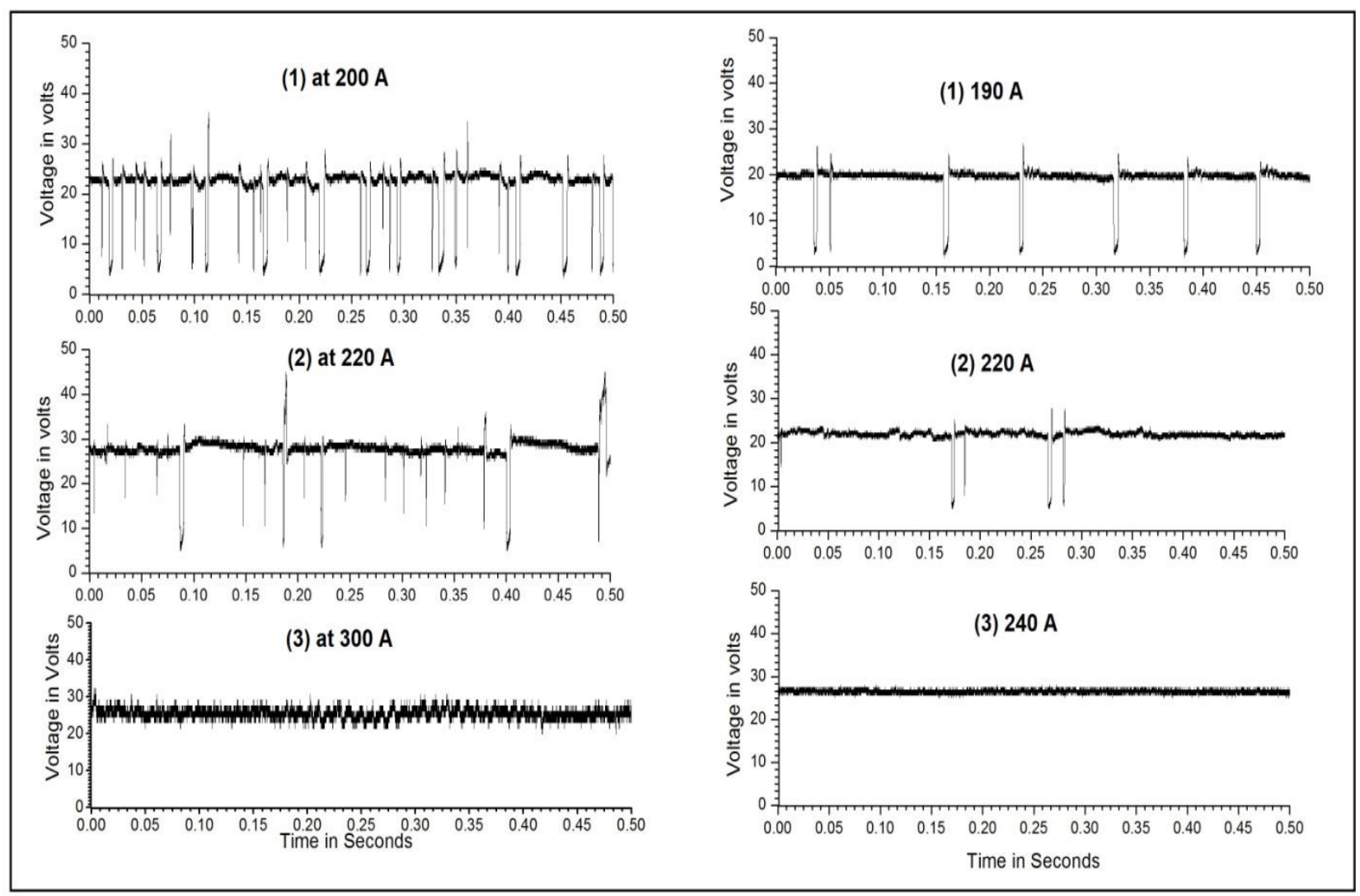

(a) $80 \% \mathrm{CO}_{2} \& 20 \% \mathrm{CO}_{2}$ shielding gas composition at (1) $200 \mathrm{~A}(2) 220 \mathrm{~A}$ and (3) $300 \mathrm{~A}$ (b) $100 \% \mathrm{Ar}$ shielding gas at (1) $190 \mathrm{~A}$ (2) $220 \mathrm{~A}$ and (3) $240 \mathrm{~A}$

Fig. 12: Time domain analysis of (a) $80 \% \mathrm{CO}_{2} \& 20 \% \mathrm{CO}_{2}$ shielding gas composition (b) $100 \% \mathrm{Ar}$ in GMAW process
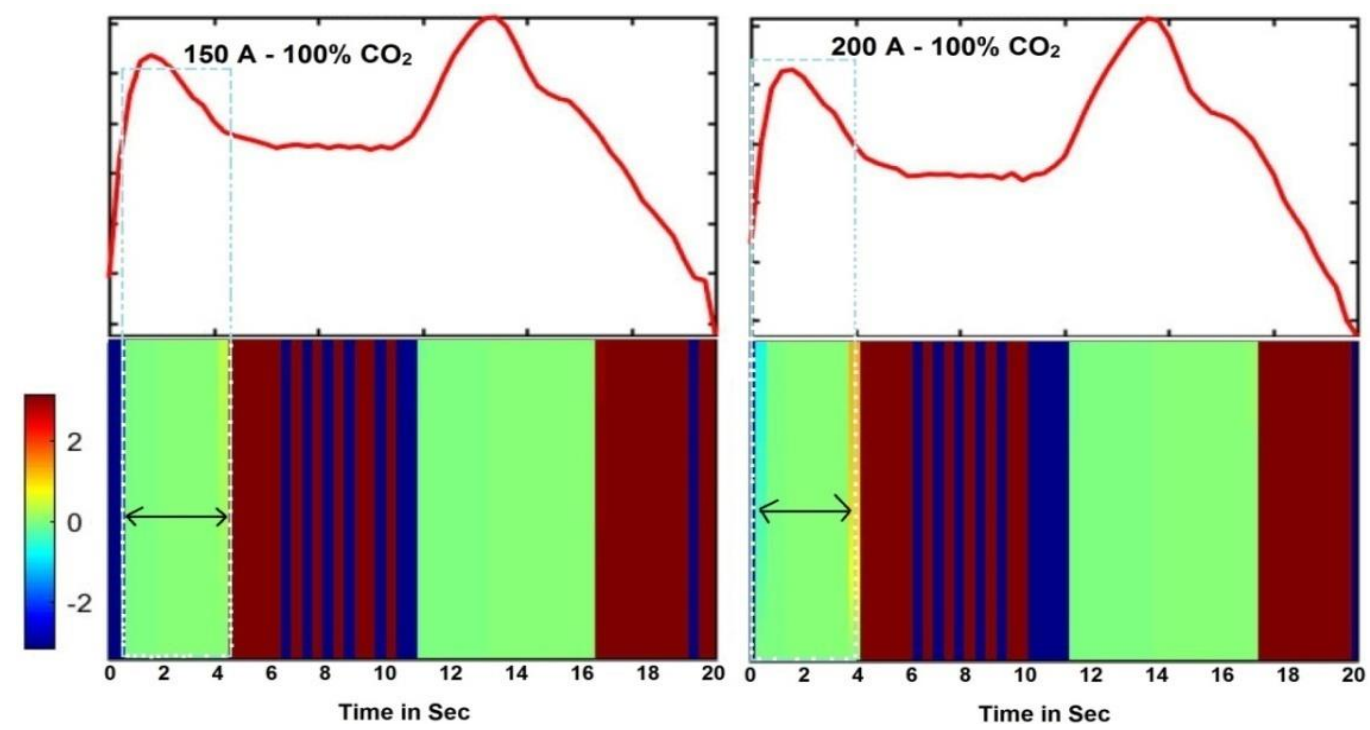

Fig. 13: CWT-FFT analysis of the voltage PDD of $100 \% \mathrm{CO}_{2}$ shielding gas (1) at $150 \mathrm{~A}$ and (2) at $200 \mathrm{~A}$ 


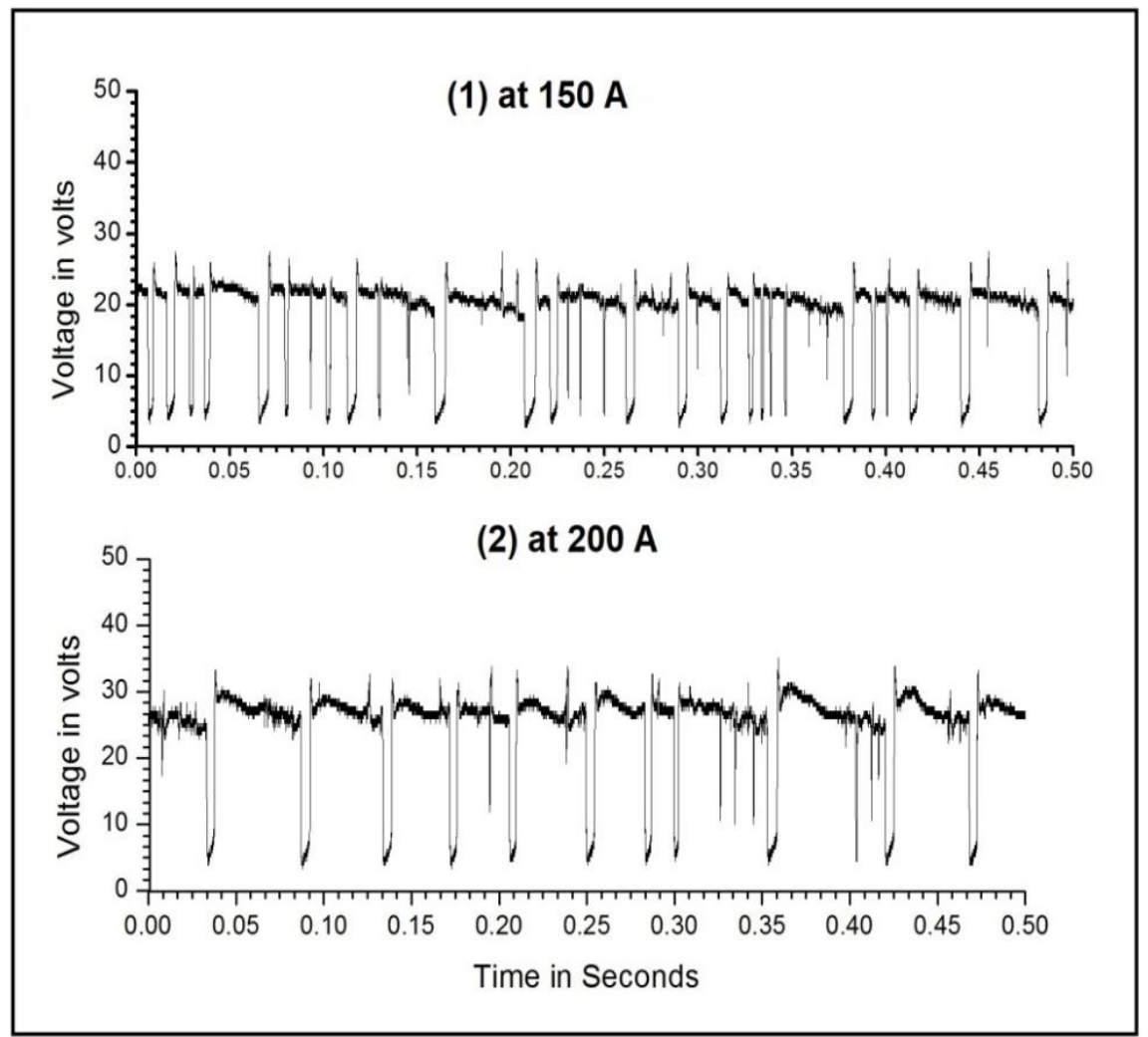

Fig. 14: Time domain analysis of (a) $100 \% \mathrm{CO}_{2}$ shielding gas at (1) $150 \mathrm{~A}$ and (2) $200 \mathrm{~A}$ in GMAW process

It is evident from the above discussions that a CWT-FFT based analysis on welding signals can easily differentiate various modes of metal transfer in the GMAW process. Hence, by monitoring the duration of various process parameters in the scalogram of a GMAW-P voltage PDD, the role of shielding gas composition on arc characteristics and the current above which spray transfer occurs can be studied.

\section{Conclusion}

In this work, the application of CWT-FFT to evaluate welding skill and welding consumables in the SMAW process and to study the effect of shielding gases with varying currents in the GMAW process are studied. From the results presented in this work one can conclude that: -

1. With the help of CWT-FFT analysis, it is possible to quantify the durations of various regions in the voltage PDDs of different trainee welders and use the same to grade their welding skills. Durations 
of steady-state welding and high voltage regions on voltage PDD changes continuously and subsequently improved as the training of the trainee's progress.

2. The proposed technique to evaluate welding skill is both time and cost-efficient as it can be used to screen or grade a large set of welders on any constructions site by just acquiring the weld data from a bead on plate weld.

3. The scalogram of the voltage PDD of one type of welding consumable is distinctly different from other scalograms. Therefore, CWT-FFT analysis can also be used to compare the performance of different welding consumables and to differentiate them. Furthermore, using the proposed technique, it should be possible to distinguish the same type of welding electrodes produced from the same kind of welding consumables manufactured by different consumable manufacturers and grade them according to their arc characteristics.

4. With CWT-FFT it is possible to study the effect of shielding gas and current combinations in a GMAW process. Scalogram of the voltage PDD obtained using CWT-FFT technique clearly differentiated the mode of metal transfer by changing gas compositions and current combinations.

\section{Acknowledgement}

The authors would like to thank Dr A. K. Bhaduri, Director, Indira Gandhi Centre for Atomic Research (IGCAR, Kalpakkam) and Central Workshop Division of IGCAR for their support and encouragement. The authors would also like to thank the Dean, School of Electronics Engineering (SOEE), Kalinga Institute of Industrial Technology (KIIT), Deemed to be University and our colleagues at KIIT for extending their genuine support to carry out this study. 


\section{Declaration}

Funding: - The authors received no financial support for this research.

Conflicts of interest / Competing interests: - The authors declare that there is no conflict of interest associated with this work.

Availability of data and material: - The authors declare that the data and the material included in the manuscript are included as electronic supplement material and are available within this article.

Code availability: - Not applicable.

Ethics approval: - One section of this study involves welder's skill classification, for this, the authors confirm that necessary permission from the institution (Indira Gandhi Centre for Atomic Research, Kalpakkam) was taken.

Consent to participate: - The authors declare that the consent from all the participating welders (involved in this study) were taken.

Consent for publication: - The authors (along with all the co-authors and whole team) approve the submission of this manuscript to be considered for publication to IJAMT. The authors have also agreed to online copy right transfer statement of the IJAMT (Springer).

Authors' contributions:- Conceptualization: Vikas Kumar and Shaju K Albert; methodology: Vikas Kumar and Manoj Kumar Parida; software: Vikas Kumar and Subhadip Ghosh; validation: Vikas Kumar and Shaju K Albert; formal analysis: Subhadip Ghosh, Vikas Kumar and Manoj Kumar Parida; investigation: Vikas Kumar, Subhadip Ghosh and Shaju K Albert; data curation: Vikas Kumar and Subhadip Ghosh; writing—original draft preparation: Vikas Kumar and Subhadip Ghosh; writing — review and editing: Shaju $\mathrm{K}$ albert and Manoj Kumar Parida; visualization and supervision: Vikas Kumar and Shaju K Albert; project administration: Shaju K Albert.

All authors have read and agreed to the drafted version of the current manuscript.

\section{References}

1. "Modern Arc Welding Technology," Ador welding limited, Oxford \& IBH publishing Co. Pvt. Ltd. New Delhi (India).

2. I. Bitharas, N. A. McPherson, W. McGhie, D. Roy, and A. J. Moore, "Visualisation and optimisation of shielding gas coverage during gas metal arc welding," Journal of Materials Processing Technology, vol. 255, pp. 451-462, May 2018, DOI: 10.1016/j.jmatprotec.2017.11.048.

3. J. Mirapeix, A. Cobo, J. Fuentes, M. Davila, J. M. Etayo, and J.-M. Lopez-Higuera, "Use of the Plasma Spectrum RMS Signal for Arc-Welding Diagnostics,” Sensors (Basel), vol. 9, no. 7, pp. 5263-5276, Jul. 2009, doi: $10.3390 / \mathrm{s} 90705263$. 
4. S. Zhang, S. Hu, and Z. Wang, "Weld penetration sensing in pulsed gas tungsten arc welding based on arc voltage," Journal of Materials Processing Technology, vol. C, no. 229, pp. 520-527, 2016, doi: 10.1016/j.jmatprotec.2015.09.034.

5. B. Chen and S. Chen, "Multi-sensor information fusion in pulsed GTAW based on fuzzy measure and fuzzy integral," Assembly Automation, vol. 30, no. 3, pp. 276-285, Jan. 2010, doi: 10.1108/01445151011061172.

6. Z. Zhang, H. Chen, Y. Xu, J. Zhong, N. Lv, and S. Chen, "Multisensor-based real-time quality monitoring by means of feature extraction, selection and modeling for Al alloy in arc welding," Mechanical Systems and Signal Processing, vol. 60, pp. 151-165, Aug. 2015, doi: 10.1016/j.ymssp.2014.12.021.

7. B. I. Kapranov and V. A. Sutorikhin, "Remote Acoustic Emission Monitoring of Metal Ware and Welded Joints," IOP Conf. Ser.: Mater. Sci. Eng., vol. 253, p. 012005, Oct. 2017, doi: 10.1088/1757-899X/253/1/012005.

8. L. Zhang, A. C. Basantes-Defaz, D. Ozevin, and E. Indacochea, "Real-time monitoring of welding process using aircoupled ultrasonics and acoustic emission," Int J Adv Manuf Technol, vol. 101, no. 5, pp. 1623-1634, Apr. 2019, doi: $10.1007 / \mathrm{s} 00170-018-3042-2$.

9. B. Zhang, Y. Shi, and S. Gu, "Narrow-seam identification and deviation detection in keyhole deep-penetration tig welding," Int. J. Adv. Manuf. Technol, Vol.101, pp. 2051-2064, 2018 , doi: https://doi.org/10.1007/s00170-0183089-0

10. H. S. Song and Y. M. Zhang, "Three-dimensional reconstruction of specular surface for a gas tungsten arc weld pool," Measurement Science and Technology, vol. 18, pp. 3751-3767, Dec. 2007, doi: 10.1088/09570233/18/12/010

11. H. Chen, K. Liu, G. Xing, Y. Dong, H. Sun, and W. Lin, "A robust visual servo control system for narrow seam double head welding robot," Int J Adv Manuf Technol, vol. 71, no. 9, pp. 1849-1860, Apr. 2014, doi: 10.1007/s00170-013-5593-6

12. B. Guo, Y. Shi, G. Yu, B. Liang, and K. Wang, "Weld deviation detection based on wide dynamic range vision sensor in MAG welding process," Int J Adv Manuf Technol, vol. 87, no. 9, pp. 3397-3410, Dec. 2016, doi: $10.1007 / \mathrm{s} 00170-016-8721-2$.

13. S. Cui, Z. Liu, Y. Fang, Z. Luo, S. M. Manladan, and S. Yi, "Keyhole process in K-TIG welding on $4 \mathrm{~mm}$ thick 304 stainless steel," Journal of Materials Processing Technology, vol. 243, pp. 217-228, May 2017, doi: 10.1016/j.jmatprotec.2016.12.027

14. Z. Liu, Y. Fang, J. Qiu, M. Feng, Z. Luo, and J. Yuan, "Stabilization of weld pool through jet flow argon gas backing in C-Mn steel keyhole TIG welding," Journal of Materials Processing Technology, vol. 250, pp. 132-143, Dec. 2017, doi: 10.1016/j.jmatprotec.2017.07.008

15. Z. Liu et al., "Sustaining the open keyhole in slow-falling current edge during K-TIG process: Principle and parameters," International Journal of Heat and Mass Transfer, vol. 112, pp. 255-266, Sep. 2017, doi: 10.1016/j.ijheatmasstransfer.2017.04.092

16. L. Massimo, S. Mirko, and R. Bruno, "Seam Welding Monitoring System Based on Real-Time Electrical Signal Analysis," Welding Journal, vol.89, pp. 218-223, 2010.

17. K. Luksa , and Z Rymarski, “ Collection of arc welding process data, " Journal of Achievements in Materials and Manufacturing Engineering, vol .17, pp. 377 - 379, 2006. 
18. L. Andrej, S. Luka, and B. Peter, Online monitoring, analysis, and remote recording of welding parameters to the welding diary, Strojniškivestnik-Journal of Mechanical Engineering, 58(7-8), pp. 444 - 452, 2012

19. V. Kumar, S. K. Albert, and N. Chanderasekhar, "Development of programmable system on chip-based weld monitoring system for quality analysis of arc welding process," International Journal of Computer Integrated Manufacturing, vol. 33, no. 9, pp. 925-935, Sep. 2020, doi: 1080/0951192X.2020.1815847

20. T. Siewert, I. Samardžić, and Š. Klarić, "Application of on-line weld monitoring system," Proceedings of the 1st DAAAM International Conference on Advanced Technologies for Developing Countries, p. 227, 2002, Accessed: Jun. 04, 2021. [Online]. Available: https://www.bib.irb.hr/76583?rad=76583

21. V. Kumar, N. Chandrasekhar, S. K. Albert, and J. Jayapandian, "Analysis of arc welding process using Digital Storage Oscilloscope," Measurement, vol. 81, pp. 1-12, Mar. 2016, doi: 10.1016/j.measurement.2015.11.031

22. V. Kumar, S. K. Albert, N. Chandrasekhar, and J. Jayapandian, "Evaluation of welding skill using probability density distributions and neural network analysis," Measurement, vol. 116, pp. 114-121, Feb. 2018, doi: 10.1016/j.measurement.2017.11.009

23. V. Kumar, S. K. Albert, N. Chandrasekhar, J. Jayapandian, and M. V. Venkatesan, "Performance analysis of arc welding parameters using self organizing maps and probability density distributions," in 2016 IEEE First International Conference on Control, Measurement and Instrumentation (CMI), Jan. 2016, pp. 196-200. doi: 10.1109/CMI.2016.7413738

24. Li, Z. Yu, and X. Dong Gao, "Study on Regression Model of Measuring Weld Position," Applied Mechanics and Materials, vol. 511-512, pp. 514-517, Feb. 2014

25. X. Li and S. W. Simpson, "Parametric approach to positional fault detection in short arc welding," Science and Technology of Welding and Joining, vol. 14, no. 2, pp. 146-151, Feb. 2009, doi: 10.1179/136217108X370272

26. S. Shin, C. Jin, J. Yu, and S. Rhee, "Real-Time Detection of Weld Defects for Automated Welding Process Base on Deep Neural Network," Metals, vol. 10, no. 3, p. 389, Mar. 2020, doi: 10.3390/met10030389

27. M. Rogfel and A. Sadek, "Data Analysis and Modeling Techniques of Welding Processes: The State-of-the-Art," Intech Open Welding-Modern topics. pp. 1-25, 2020.

28. L. Yang and H. Jiang, "Weld defect classification in radiographic images using unified deep neural network with multi-level features," J Intell Manuf, vol. 32, no. 2, pp. 459-469, Feb. 2021, doi: 10.1007/s10845-020-01581-2.

29. S. B. Chen and N. Lv, "Research evolution on intelligentized technologies for arc welding process," Journal of Manufacturing Processes, vol. 16, no. 1, pp. 109-122, Jan. 2014, doi: 10.1016/j.jmapro.2013.07.002.

30. B. Das, S. Pal and S. Bag, "A combined wavelet packet and Hilbert-Huang transform for defect detection and modelling of weld strength in friction stir welding process," J Manuf Process, vol. 22 , pp. 260-268, 2016.

31. N. Lv, Y. Xu, Z. Zhang, J. Wang, B. Chen, and S. Chen, "Audio sensing and modeling of arc dynamic characteristic during pulsed Al alloy GTAW process," Sensor Review, vol. 33, no. 2, pp. 141-156, Jan. 2013, doi: $10.1108 / 02602281311299680$.

32. Y. Cui, Y. Shi, Tao Zhu and S. Cui, "Welding penetration recognition based on arc sound and electrical signals in K-TIG welding, "Measurement, vol. 163, 2020, doi: https://doi.org/10.1016/j.measurement.2020.107966

33. W. Zhou, Q. Li and Z.Zhou, "Power Quality Detection Using Wavelet-Multiresolution Signal Decomposition," Transactions of China Electrotechnical Society, vol.16(6), pp. 81-84, 2001. 
34. Z. Zhou and C.Guan, "Wavelet image de-noising based on multi-scale edge detection and adaptive threshold," Chinese Journal of Scientific Instrument, vol.28(2), pp. 288-292, 2007.

35. W. Yu, G. Dalu and L. Mingfu, "A Better Method for Detecting Friction Welding Defect," Journal of Northwestern Polytechnical University, vol. 23(4), pp. 496-499, 2005.

36. K. He, Z. Zhou, C. Wang, and X. Li, “Arc signal analysis of square wave alternating current submerged arc welding using local mean decomposition," Journal of Advanced Mechanical Design, Systems, and Manufacturing, vol. 10, no. 9, pp. JAMDSM0104-JAMDSM0104, 2016, doi: 10.1299/jamdsm.2016jamdsm0104

37. U. Kumar et al., "Defect identification in friction stir welding using discrete wavelet analysis," Advances in Engineering Software, vol. 85, pp. 43-50, Jul. 2015, doi: 10.1016/j.advengsoft.2015.02.001

38. R. Caglar, "Wavelet transform and current signature analysis for welding machine measurement," Journal of Vibroengineering, vol. 14, no. 2, pp. 805-812, 2012, Accessed: Jun. 04, 2021. [Online]. Available: https://www.jvejournals.com/article/10638

39. C. Torrence and G. P. Compo, "A Practical Guide to Wavelet Analysis," Bulletin of the American Meteorological Society, vol. 79, no. 1, pp. 61-78, Jan. 1998, doi: 10.1175/1520- 0477(1998)079<0061:APGTWA>2.0.CO;2

40. O. Rioul and M. Vetterli, "Wavelets and signal processing," IEEE Signal Processing Magazine, vol. 8, no. 4, p. 14, 1991, doi: 10.1109/79.91217.

41. D. Komorowski and S. Pietraszek, "The Use of Continuous Wavelet Transform Based on the Fast Fourier Transform in the Analysis of Multi-channel Electrogastrography Recordings," J Med Syst, vol. 40, no. 1, p. 10, Oct. 2015, doi: 10.1007/s10916-015-0358-4

42. Steinbuch, M., and van de Molengraft, M. J. G., Eindhoven. University of Technology, Control Systems Technology Group, Eindhoven, Wavelet Theory and Applications, a literature study. R.J.E. Merry, DCT, 2005.53.

43. Oppenheim, A. V., Schafer, R. W., and Buck, J. A., Discrete-time signal processing. Upper Saddle River, N.J.: Prentice Hall. ISBN. 0137549202, 1999

44. V. Kumar, S. K. Albert, N. Chanderasekhar and J. Jayapandian., " Performance Evaluation of Arc Welding Process Using Weld Data Analysis," Trans Indian Inst Met, vol. 71, pp. 3063-3075, 2018, doi: https://doi.org/10.1007/s12666-018-1450-5

45. Craig., Gas Metal Arc and Flux Cored Welding Parameters, A unique Approach to Parameters, Weld Quality, and Weld Costs.

46. O’Brien, welding hand Book 8th edition volume 2, welding process, American Welding Society. 